\title{
Justyna Skrzypnik
}

Uniwersytet Śląski w Katowicach

e-mail: j.k.skrzypnik@gmail.com

\section{Kulturowy interfejs Google: paradyğmat audiowizualności w uniwersum slowa}

\section{Abstract \\ Google's Cultural Interface: The Paradigm of Audiovisuality in the Universe of Words}

Although the Google search engine is considered as the nervous system of the Internet, its role in the new media universe is still undetermined. The search engine, placed between the Web 2.0 medium and the mechanism of content selection, is ambigous, and its website can be easily distinguished from social media news feeds. As for the domination of visual content, SERP can be considered as the last stand of the words in the iconosphere. In the context of the digital content and its representation, the borders between verbal and visual communication are fluid and mistakable, while the relations between them can be discussed in a wider cultural context.

Keywords: search engines, Google search engine, image in the Internet, word in the Internet

Słowa kluczowe: wyszukiwarki internetowe, Google, słowo w sieci, obraz w sieci

Paradygmat audiowizualności współczesnej kultury zdominował refleksję nad usieciowioną rzeczywistością nowych mediów. Ikonosfera internetu, budowana na różnorodnych formach reprezentacji wizualnej, przyrównywana jest wielokrotnie do świata „prostej formy komunikacji, stosowanej już przez pierwsze cywilizacje, 
przed tysiącami lat"1. Pokusa postrzegania zwrotu piktograficznego ${ }^{2}$ jako procesu kierującego rozwój kultury oraz jej narzędzi w stronę pierwotnych form kulturowo-cywilizacyjnych może implikować strukturalistyczne pragnienie uporządkowania historii mediów w swoistą matrycę pojęciową. W jej ramach możliwe byłoby zestawienie z sobą szeregów binarnych opozycji, takich jak: linearność/nielinearność, ciągłość/nieciągłość, myślenie kategoriami abstrakcyjnymi/nastawienie na konkret czy nawet rozwój cywilizacyjny/kulturowy regres i przyporządkowanie szeregów binarnych opozycji naczelnym kategoriom cyrograficzności i ikoniczności. Zapoczątkowana u schyłku XX wieku idea dominacji ikonosfery w kulturze uległa transformacji w dobie upowszechnienia komunikacji sieciowej, tak jak przedefiniowana została sama kategoria obrazu. Sposób funkcjonowania wizualnych reprezentacji świata w sieci jest bowiem znacząco różny od charakteru obrazów w świecie analogowym $^{3}$. Na rozumienie przedstawień wizualnych w sieci składają się różnorodne formy reprezentacji, kreacji bądź symulacji rzeczywistości, osadzone w kontekście platform medialnych i sieciowych interfejsów, które implikują odmienny dla każdego z nich status obrazów.

\section{Paradygomat wizualności w platformach medialnych Web 2.0}

Medium, w którym osadzony jest dany obraz, determinuje jego charakter, przetwarza go, włącza w obręb interfejsu i stanowi kontekst jego funkcjonowania. Obraz osadzony w levinsonowskich nowych nowych mediach ${ }^{4}$ jest każdorazowo częścią składową news feeda, tablicy, SERP (search engine results page) - multimedialnego strumienia ikon, zdjęć, grafik, dźwięków, filmów, słów, tagów i hiperłączy. Są one porządkowane i selekcjonowane na podstawie matematycznej logiki algorytmu i przyswajane w formie, którą Lev Manovich przyrównuje do zwoju papirusu, stopniowo skanowanego przez użytkownika w poszukiwaniu treści przykuwających wzrok i uwagę ${ }^{5}$. Obraz jest zatem częścią strumienia danych, wyrażonych werbalno-wizualnym językiem sieci ${ }^{6}$. Słowo jest immanentną częścią przekazu obrazowego, jest z nim zespolone, uzupełnia i opisuje bądź dopowiada treści do komunikatu wizualnego. Wtórnie

${ }^{1}$ M. Szpunar, Kultura obrazu a ikonosfera Internetu, „Studia Medioznawcze” 2008, nr 3, s. 105-124.

2 W.J.T. Mitchell, Pokazując widzenie: krytyka kultury wizualnej, tłum. M. Bryl, „Artium Quaestiones" 2006, nr XVII, s. 238.

${ }^{3}$ T. Ferenc, K. Olechnicki, Dlaczego warto badać obrazy w sieci [w:] T. Ferenc, K. Olechnicki (red.), Obrazy w sieci. Socjologia i antropologia ikonosfery internetu, Toruń 2009, s. 9.

${ }^{4}$ P. Levinson, Nowe nowe media, tłum. M. Zawadzka, Kraków 2010.

${ }^{5}$ L. Manovich, Język nowych mediów, tłum. P. Cypryański, Warszawa 2006, s. 158.

${ }^{6}$ N. Pater-Ejgierd, Dlaczego sieć przemawia obrazem? [w:] K. Olechnicki, T. Ferenc (red.), Obra$z y$ w sieci..., s. 33 . 
oralny charakter słowa $\mathrm{w}$ sieci $^{7}$ przekłada się na jego ożywienie, zastąpienie wpisanej w słowo nieobecności ${ }^{8}$ teleobecnością i osadzenie w internetowym „tu i teraz”. Werbalno-wizualny język sieci dowartościowuje aktualność, świeżość komunikatów, eksploatując potencjał komunikacji wizualnej do przenoszenia sensów w przestrzeni. Obraz w sieci Web 2.0 i nowych nowych mediach, opatrzony werbalnym komentarzem, coraz częściej osadzony jest w czasie rzeczywistym, zbliża się do transmisji na żywo (zarówno w postaci transmisji audiowizualnych, jak i bieżącego relacjonowania doświadczeń za pomocą zdjęć i grafik).

Prymarny charakter treści wizualnych w strumieniach internetowych interfejsów można przypisać portalom społecznościowym, takim jak Instagram, Pinterest, Snapchat czy - w mniejszym stopniu - Facebook, w przypadku których kod wizualny jest podstawowym nośnikiem treści. Obok fotografii, grafik, gifów czy filmów, wizualizacji podlegają także komunikaty tekstowe ${ }^{9}$, czy to $\mathrm{w}$ formie sygnatur ${ }^{10}$, nasycenia tekstu emotikonami ${ }^{11}$, czy jego wizualizacji. News feedy Instagrama czy Pinteresta, stanowiące swoiste kolaże komunikatów wizualnych, tablice Facebooka czy Twittera, będące konglomeratami treści wizualnych i zwizualizowanych, przesądzają o ikonocentryczności przekazów w mediach Web 2.0. W żaden z powyższych modeli nie wpisuje się jednak strona wyników wyszukiwania SERP w Google.

\section{Paradygimat audiowizualności a SERP}

Wyszukiwarka Google, choć stanowi rdzeń sieci Web 2.0 i jest określana mianem „układu nerwowego Internetu” ${ }^{2}$, nie jest jednoznacznie uznawana za nowe medium. Paul Levinson, obok poczty elektronicznej i elektronicznych systemów płatności, uznaje ją za „podstawę funkcjonowania nowych nowych mediów”" ${ }^{13}$, zaznacza jednak jasno, że nie wchodzi ona w ich obręb. Platformy Google od wielu lat wykraczają już jednak poza funkcjonalność wyszukiwarki jako takiej. Jak wskazuje Alexander Halavais:

Choć wyszukiwarka jest zwykle systemem, który indeksuje strony internetowe, termin uległ rozszerzeniu i obejmuje obecnie również wiele środowisk informacyjnych i form medialnych,

7 W.J. Ong, Oralność i piśmienność. Słowo poddane technologii, tłum. J. Japola, Lublin 1992, s. 32.

${ }^{8}$ J. Derrida, Pismo i telekomunikacja, „Teksty: Teoria Literatury, Krytyka, Interpretacja” 1975, nr 3(21), s. 83.

9 P. Celiński, Postmedia. Cyfrowy kod i bazy danych, Lublin 2013, s. 7.

${ }_{10}$ M. Szpunar, Kultura obrazu..., s. 105-124.

${ }^{11}$ U. Żydek-Bednarczuk, Tekst w Internecie i jego wyznaczniki [w:] M. Kita (red.), Dialog a nowe media, Katowice 2004, s. 5.

${ }_{12}$ P. Levinson, Nowe nowe media..., s. 13.

13 Tamże. 
łącznie z multimediami i inną treścią znajdującą się w wewnętrznych sieciach komputerowych i na pojedynczych komputerach ${ }^{14}$.

Google, stanowiąc zbiór zintegrowanych z sobą platform i serwisów, nie jest już tylko mechanizmem wyszukiwania. Poboczne względem wyszukiwarki usługi internetowe, takie jak Gmail, Google Translate, Google+, Google Dysk, Google Books, Hangouts i wiele innych, stanowią platformy służące do pozyskiwania i gromadzenia danych o użytkownikach, będących podstawowym kapitałem Google. Jednak flagowymi projektami Google pozostają ciągle Google Search i Google Display Network, które w największym stopniu przyczyniają się do monetyzacji kapitału internetowego giganta. W samym zaś centrum tychże projektów jest strona wyników wyszukiwania, prezentująca 10 najpopularniejszych - czy może: najlepiej wypozycjonowanych wyników stanowiących odpowiedzi na wpisane zapytanie. Wygląd i funkcjonalność SERP w Google podlegają nieustannym zmianom, a wraz z kolejnymi modyfikacjami wizualny układ treści coraz mniej przypomina pierwotny charakter prostego rankingu wyszukiwań. Kolejne zmiany, wprowadzane w obręb strony wyników wyszukiwania, ukierunkowane są na przekształcenie jej w swego rodzaju supermedium, agregujące zasoby sieciowe i „wchłaniające” treści opublikowane uprzednio przez inne podmioty. Google ogranicza przy tym do minimum konieczność eksponowania źródeł treści, które prezentuje w wynikach wyszukiwania. Jak wynika z badania Instytutu Studiów nad Dziennikarstwem Reutersa na Uniwersytecie Oksfordzkim, działania Google, mające na celu zatrzymanie użytkownika na stronie wyników wyszukiwania i zniechęcanie go do przechodzenia na inne strony, wykazują się wysoką skutecznością - aż 63\% użytkowników wyszukiwarki nie jest w stanie powiązać przeczytanej treści z podmiotem, który ją opublikowa ${ }^{15}$. Wśród wdrażanych przez Google funkcjonalności, zorientowanych na zatrzymanie użytkowników na stronie wyników wyszukiwania, można wyróżnić rozwiązania takie jak uruchomiony w kwietniu 2016 roku boks Direct Answers ${ }^{16}$. Dzięki niemu uzyskanie odpowiedzi na wpisane w wyszukiwarkę pytanie nie wymaga przekierowania na inną stronę, gdyż zwięzła i konkretna odpowiedź wyświetla się bezpośrednio w SERP. Obok boksu Direct Answers w wyszukiwarce Google wyświetlane jest także pole Feedback, stanowiące zestawienie danych - zdjęć, map, tekstów, filmów i przekierowań. Pole to, w zależności od charakteru zapytania, przybiera różne formy - od metryk znanych osób, wzbogaconych zdjęciami i odnośnikami do mediów społecznościowych, przez mapki i wykresy pogodowe, aż po teledyski i nagrania odsyłające na przykład do

${ }^{14}$ A. Halavais, Wyszukiwarki internetowe a społeczeństwo, tłum. T. Płudowski, Warszawa 2012, s. 20.

${ }_{15}$ A. Kalogeropoulos, N. Newman, „I Saw the News on Facebook” Brand Attribution When Accessing News from Distributed Environments, Oxford 2017, s. 7.

${ }_{16}$ T. Stopka, Co to jest Direct Answers - jak osiagnać pozycje „zero” w Google?, 2016, http://antyweb.pl/direct-answers/ [odczyt: 20.10.2017]. 
portalu YouTube. Kolejnym krokiem w kierunku zatrzymania użytkownika w SERP jest wdrożenie funkcjonalności People Also Ask, dostępnej w anglojęzycznej wersji wyszukiwarki. W ramach People Also Ask Google podpowiada użytkownikowi kolejne pytania, będące rozwinięciem otrzymanych już wyników. Ponadto w skład boksu wchodzą rozwijane pola, zawierające konkretne, rzeczowe i łatwe do przyswojenia odpowiedzi.

Przekształcenia strony wyników wyszukiwania Google świadczą o przesunięciu roli wyszukiwarki: od minimalistycznego wizualnie katalogu przekierowań, składającego się jedynie z metatytułów, metaopisów i właściwych linków, do spersonalizowanej, interaktywnej tablicy skojarzeń, rozwijanej podobnie do przytaczanego już zwoju papirusu ${ }^{17}$. Przejście od opartego na słowie rankingu najtrafniejszych (według algorytmu Google) wyników wyszukiwania do rozbudowanej, komponowanej kontekstowo strony, stanowiącej konglomerat treści wizualnych, audiowizualnych i werbalnych, ostatecznie pozwala na osadzenie Google w kontekście paradygmatu wizualności komunikatów. Podczas gdy tradycyjna wersja SERP była hipertekstową listą odnośników, współczesny układ treści na stronie wyników wyszukiwania bazuje opiera się na logice wizualnej, u podstaw której leży: „przestrzenna organizacja i symultaniczność (równoczesna ekspresja wielu elementów). Logika wizualna jest logiką układu (arrangement) i displayu (gdzie display polega na pokazaniu najważniejszych elementów świata i przestrzennych relacji pomiędzy nimi)"18.

Logika SERP nie jest jednak tylko logiką wizualności. Rezultaty wyszukiwania prezentowane są wprawdzie w ujednoliconej i standaryzowanej formie tekstowej, jednak w zestawieniu $\mathrm{z}$ innymi treściami nabierają one charakteru swoistych "obrazotekstów"19. Tekst podlegający ścisłym rygorom formatowania przestrzennego traci status słowa pisanego, zmienia swoje podstawowe funkcje ${ }^{20} \mathrm{i}$ przekształca się w hipertekst. W przypadku SERP wykracza on poza właściwą tej kategorii interaktywność. Składające się na niego treści uwarunkowane są nie tylko świadomą aktywnością użytkownika, wybierającego określone ścieżki odbioru, lecz przede wszystkim - są personalizowane na podstawie zbieranych przez Google danych o jego zachowaniach, nie tylko $\mathrm{w}$ sieci, lecz także w świecie off-line ${ }^{21}$. Strumień danych, selekcjonowanych przez algorytmy Google, uwarunkowany jest nie tylko sposobem, w jaki użytkownik podąża za wybranymi przez siebie odnośnikami, lecz także jego lokalizacją, trybem przemieszczania się i zachowaniem w świecie

${ }^{17}$ L. Manovich, Język nowych mediów..., s. 158.

${ }_{18}$ M. Górska-Olesińska, Słowo w sieci. Elektroniczne dyskursy, Opole 2009, s. 23.

19 Tamże, s. 15.

${ }^{20}$ A. Gwóźdź, Technologie widzenia, czyli media w poszukiwaniu autora: Wim Wenders, Kraków 2004, s. 98.

${ }^{21}$ K. Kozłowski, Historia lokalizacji Google w przeglądarce jest jeszcze bardziej przerażająca, http:// antyweb.pl/historia-lokalizacji-google-w-przegladarce-jest-jeszcze-bardziej-przerazajaca/ [odczyt: 20.10.2017]. 
rzeczywistym. Strona wyników wyszukiwania ma strukturę fraktalną i jest budowana na zasadzie wariacyjnego łączenia $\mathrm{z}$ sobą określonych modułów ${ }^{22}$. Jest przy tym skonstruowania na podstawie „usieciowionej składni przestrzennej obrazów tekstu i ikon", co pociąga za sobą zmniejszenie znaczenia form dyskursywnych i zastąpienie ich strategiami przedstawiającymi ${ }^{23}$.

Rozwijanie audiowizualnego, modularnego charakteru interfejsu Google, z którym interakcja wpisana jest w codzienne doświadczenie usieciowionego człowieka, implikuje wzmacnianie paradygmatu wizualności jako wzoru współczesnej kultury. Zaimplementowany na grunt Google „hipertekstowy model WWW organizuje świat jako system niezhierarchizowany, oparty na metonimii" ${ }^{24}$, tworząc tym samym iluzję egalitarności kultury, na którą oddziałuje. Fasadowy charakter tego porządku wynika z głębokiej dysproporcji pomiędzy charakterem interfejsu a mechanizmem algorytmu. O ile bowiem przyjmując perspektywę użytkownika, można uznać Google za środowisko realizowania się paradygmatu wizualności, o tyle przyjmując perspektywę ukierunkowanych na widoczność w sieci autorów treści i twórców internetowych interfejsów, Google jawi się jako uniwersum słowa przetranskrybowanego na kod zerojedynkowy. W środowisku zdeterminowanym przez aktywność algorytmów selekcjonujących informacje i wyznaczających zasady ich redagowania nowego znaczenia nabiera sygnalizowana już nowomedialna „logowizualność” 25 . Aby treści internetowe, zarówno wizualne, audialne, jak i werbalne, mogły być czytelne dla botów indeksujących, muszą być opisane słownymi parametrami, sformułowanymi w sposób umożliwiający powiązanie ich przez mechanizm wyszukiwania z określonymi zapytaniami użytkowników. Różnorodne sieciowe formy obrazowania, takie jak zdjęcia, grafiki, animacje itd., by mogły być „widzialne” dla botów indeksujących, muszą stanowić nowego rodzaju „obrazotekst” - treść obrazową, opatrzoną i dookreśloną przez słowo. Nie jest to jednak dookreślenie w rodzaju podpisu czy etykiety - słowo jest w tym ujęciu immanentną częścią obrazu, jego dopełnieniem, rewersem bądź translacją. Podstawą wszelkich treści widocznych w Google jest zatem słowo.

W uniwersum Google słowo zyskuje dodatkową funkcję, polegającą na oznaczaniu treści w sposób czytelny dla botów indeksujących. Treści internetowe wymagają swego rodzaju podwójnego kodowania, z jednej strony - ukierunkowanego na ludzkiego odbiorcę języka obrazów, dźwięków i tekstów, z drugiej - systemu metaznaczników, tłumaczących wszystkie te typy komunikatów na słowa możliwe do zdekodowania przez boty. Mechanizm ten dotyczy dwóch rodzajów kodu werbalnego funkcjonujących w wyszukiwarce. Pierwszym z nich są słowa czy też frazy

${ }_{22}$ L. Manovich, Język nowych mediów..., s. 103-104,

${ }^{23}$ A. Gwóźdź, Technologie widzenia..., s. 98.

${ }^{24}$ L. Manovich, Język nowych mediów..., s. 142.

${ }^{25}$ A. Gwóźdź, Technologie widzenia..., s. 96. 
kluczowe (keywords), którymi nasycony jest tekst i które są przyporządkowane do treści wizualnych w postaci niewidocznych dla użytkownika znaczników. Pozwalają one botom indeksującym dopasować treści do konkretnego zbioru zagadnień. Drugim typem są słowa będące immamentną częścią kodu programistycznego, słowa-wskazówki dla botów, określające sposób, w jaki mają one indeksować treść (np. nakazujące [dofollow] lub zakazujące [nofollow] im podążać za konkretnym linkiem). W słowach kluczach można upatrywać kolejnej, po związanych z drukiem skorowidzach, nagłówkach i indeksach ${ }^{26}$, formy organizowania treści, zwalniającej użytkownika z całościowego, linearnego przyswajania tekstu. W konsekwencji percypowanie treści przez ludzi upodabnia się do procesu indeksowania sieci przez boty.

\section{Ku algorytmom rozpoznawania obrazu}

Rozwój interfejsów Web 2.0 w kierunku audiowizualności implikuje także zmiany w sposobie działania algorytmów. Powstawanie programów indeksujących i selekcjonujących treści na podstawie danych sensu stricto wizualnych, bez odniesienia do słownych metaznaczników, pociąga za sobą zmniejszenie roli algorytmów bazujących na materiale werbalnym. Nie zmienia to jednak werbalno-wizualnego charakteru interakcji użytkownika $\mathrm{z}$ wyszukiwarką. Algorytmy analizujące treść obrazów, przetwarzając dane dotyczące relacji pomiędzy różnokolorowymi pikselami, zestawiają bowiem informacje pozyskane z danych graficznych z kontekstem, $\mathrm{w}$ jakim występują ${ }^{27}$. Są zatem w znacznym stopniu osadzone w werbalnie zdeterminowanym uniwersum Google.

Komunikat selekcjonowany i publikowany przez Google funkcjonuje zatem na kilku poziomach języka. W pierwszej kolejności jest to poziom języków: wizualnego i audiowizualnego, które są ukierunkowane na użytkowników sieci, korzystających $\mathrm{z}$ usług Google produseró $w^{28}$ konsumujących, przetwarzających, publikujących swoje warianty internetowych treści. Konsekwencje dominacji tak rozumianego paradygmatu wizualności w sieci trafnie ujmuje Piotr Celiński, pisząc:

Na obecnym etapie rozwoju cyfrowych form technologicznych (hardware i software) wizualność jest przede wszystkim praktyką nadawania surowym, matematycznym ciągom kodu baz danych bezpiecznych antropologicznie (psychologia i antropologia postrzegania) i kulturowo (semiotyka wizualności) kształtów, tj. upodabniania do oswojonych w ramach dziedzictwa visual culture form (np. ekran monitora jako nawiązanie do ekranu telewizora, strona www

${ }^{26}$ W.J. Ong, Oralność i piśmienność..., s. 167-170.

27 A. Serafinowicz, Wyszukiwanie obrazem - Google, TinEye i inni, http://softonet.pl/publikacje/ poradniki/Wyszukiwanie.obrazem-Google.TinEye.i.inni,915 [odczyt: 20.10.2017].

${ }^{28}$ J. Kreft, Za fasada społeczności, Kraków 2015, s. 61. 
jako nawiązanie do drukowanej gazety). Inaczej mówiąc: obrazy wystawiamy jako najważniejszy kulturowy kapitał/system bezpieczeństwa w kontaktach z niewidzialnym, tj. trudnym do uchwycenia (za sprawą miniaturyzacji narzędzi i spektrum widzialności elektryczności) techné, a przez to niezrozumiałymi/groźnymi elektrycznością, kodem cyfrowym i oceanem digitalnych danych. W ten sposób wizualność pełni nie tylko rolę gwaranta kulturowego bezpieczeństwa i uniwersalnej powłoki (mapy) cyfrowych wód, siłą rzeczy przekształcona została także - dopełniając historię analogowej mediatyzacji wizualności - w najpowszechniejszą praktykę użytkową nowych technologii, stając się gruntem, na którym narodziły się ich interfejsy. Najogólniej rzecz ujmując, przypomnę: obrazy stały się najważniejszym kulturowym interfejsem technologii rewolucji cyfrowej ${ }^{29}$.

Zwiększenie udziału komunikatów obrazowych w sieci i ich prymarny względem treści werbalnych charakter determinuje pogłębienie podziału pomiędzy „biernymi” odbiorcami internetowych treści a użytkownikami tworzącymi je ze świadomością sposobu funkcjonowania algorytmów oraz twórcami kodu. Język interfejsu Google ma charakter hybrydyczny i składa się nie tylko z treści funkcjonujących dotąd w innych obszarach kultury - werbalnych, ikonicznych i audialnych - lecz także z logiki interfejsu, zasad środowiska i programistycznych frameworków ${ }^{30}$. Dominującym typem kodu dla przedstawicieli tej drugiej grupy jest kod werbalny, osadzony w szerszym kontekście kodu programistycznego. Treści w odpowiedni sposób nasycone słowami kluczowymi, słowa opatrzone znacznikami i uzupełnione fragmentami kodu składają się na przekazy tworzone z myślą nie tylko o użytkownikach, lecz także - często przede wszystkim - z myślą o botach indeksujących. Postępująca wizualizacja - czy audiowizualizacja - treści internetowych pogłębia zatem podział na użytkowników zaznajomionych z kodem oraz „kodowych analfabetów”. Jak pisze Lev Manovich: „[wprowadzanie nowych języków programowania] można rozumieć jako element strategii mającej na celu utrzymanie różnic pomiędzy profesjonalistami i zwykłymi użytkownikami komputerów" ${ }^{31}$.

Użytkownicy świadomi sposobu działania kodu, posługujący się metaznacznikami, zachowują wpływ na selekcję treści w Google, manipulując poniekąd funkcjonowaniem algorytmu. Równocześnie odbiorcy kodu biernie korzystający z intuicyjnych interfejsów konsumują treści podawane im przez algorytm, wierząc w ideę społecznościowego wyszukiwania ${ }^{32}$. Możliwość regulowania dostępu do informacji pociąga za sobą potencjalność władzy. Użytkownicy algorytmu, mający możliwość wpływania na największego internetowego gatekeepera, zyskują poniekąd władzę nad informacjami, które docierają do „kodowych analfabetów”.

29 P. Celiński, Postmedia..., s. 162.

${ }^{30}$ L. Manovich, Język nowych mediów..., s. 174.

31 Tamże, s. 209.

32 A. Halavais, Wyszukiwarki internetowe..., s. 195-217. 
Dwoisty, werbalno-wizualny strumień internetowych treści, mimo iż jest ostatecznie ujednolicany do trzeciego typu kodu: reprezentowanego numerycznie zapisu cyfrowego, na poziomie kulturowego interfejsu wpływa na sposoby myślenia i postrzegania świata i „organizując dane komputerowe na różne sposoby, ustanawia różne modele świata" ${ }^{33}$. Z kolei pogłębiane zróżnicowanie języków i - co za tym idzie użytkowników sieci może implikować zmniejszenie (czy nawet zanik) dyskursywności komunikacji internetowej na rzecz „przedstawienia” i „algorytmizacji”. Świat Google nie jest zatem ani uniwersum słowa, ani uniwersum obrazu. Interfejs wyszukiwarki podyktowany jest specyfiką algorytmu, który nabiera charakteru kulturotwórczego, jednocześnie pozostając za audiowizualną fasadą sieci Web 2.0.

\section{Bibliografia}

Battelle J., Szukaj. Jak Google i konkurencja wywołali biznesowa i kulturowa rewolucje, tłum. M. Baranowski, Warszawa 2007.

Celiński P., Postmedia. Cyfrowy kod i bazy danych, Lublin 2013.

Derrida J., Pismo i telekomunikacja, „Teksty: Teoria Literatury, Krytyka, Interpretacja” 1975, nr 3(21), s. 75-92.

Ferenc T., Olechnicki K., Dlaczego warto badać obrazy w sieci [w:] K. Olechnicki, T. Ferenc (red.), Obrazy w sieci. Socjologia i antropologia ikonosfery internetu, Toruń, 2009, s. 3-12.

Flusser V., Ku filozofii fotografii, tłum J. Maniecki, Katowice 2004.

Górska-Olesińska M., Słowo w sieci. Elektroniczne dyskursy, Opole 2009.

Gwóźdź A., Technologie widzenia, czyli media w poszukiwaniu autora: Wim Wenders, Kraków 2004. Halavais A., Wyszukiwarki internetowe a społeczeństwo, tłum. T. Płudowski, Warszawa 2012.

Kalogeropoulos A., Newman N., „I Saw the News on Facebook”. Brand Attribution when Accessing News from Distributed Environments, Oxford 2017.

Kozłowski K., Historia lokalizacji Google w przegladarce jest jeszcze bardziej przerażająca, http:// antyweb.pl/historia-lokalizacji-google-w-przegladarce-jest-jeszcze-bardziej-przerazajaca/ [odczyt: 20.10.2017].

Kreft J., Za fasadą społeczności, Kraków 2015.

Levinson P., Nowe nowe media, tłum. M. Zawadzka, Kraków 2010.

Manovich L., Język nowych mediów, tłum. P. Cypryański, Warszawa 2006.

Mitchell W.J.T., Pokazując widzenie: krytyka kultury wizualnej, tłum. M. Bryl, „Artium Quaestiones" 2006, nr XVII.

Ong W.J., Oralność i piśmienność. Słowo poddane technologii, tłum. J. Japola, Lublin 1992.

Pater-Ejgierd N., Dlaczego sieć przemawia obrazem?, [w:] K. Olechnicki, T. Ferenc (red.), Obrazy $w$ sieci. Socjologia i antropologia ikonosfery internetu, Toruń 2009, s. 28-66.

${ }^{33}$ L. Manovich, Język nowych mediów..., s. 142. 
Stopka T., Co to jest Direct Answers - jak osiagnać pozycję „zero” w Google?, 2016, http://antyweb.pl/direct-answers/ [odczyt: 20.10.2017].

Szpunar M., Kultura obrazu a ikonosfera Internetu, „Studia Medioznawcze” 2008, nr 3, s. 105-124. Serafinowicz A., Wyszukiwanie obrazem - Google, TinEye i inni, http://softonet.pl/publikacje/ poradniki/Wyszukiwanie.obrazem-Google.TinEye.i.inni,915 [odczyt: 20.10.2017].

Vise D.A., Malseed M., Google Story / Inside the Hottest Business, Media and Technology Success of Our Time, New York 2005.

Żydek-Bednarczuk U., Tekst w Internecie i jego wyznaczniki [w:] M. Kita (red.), Dialog a nowe media, Katowice 2004, s. 10-19. 